\title{
Helicobacter pylori Eradication for Metachronous Gastric Cancer: An Unsuitable Methodology Impeding Broader Clinical Usage
}

\author{
Alexios-Fotios A. Mentis ${ }^{1,2 \star}$ and Efthimios Dardiotis ${ }^{3}$ \\ ${ }^{1}$ Public Health Laboratories, Hellenic Pasteur Institute, Athens, Greece, ${ }^{2}$ Department of Microbiology, University Hospital of \\ Larissa, University of Thessaly, Larissa, Greece, ${ }^{3}$ Department of Neurology, University Hospital of Larissa, University of \\ Thessaly, Larissa, Greece
}

Keywords: Helicobacter pylori, gastric cancer, infection, antibiotic therapy, clinical trial, pathogen

\section{INTRODUCTION}

Recently, a study reported significant reductions in metachronous gastric cancer after $H$. pylori eradication therapy in patients with previously resected early gastric cancer. These results indicated that $H$. pylori infections benefit from treatment at any stage, thus refuting the conventional concept of the "point of no return". Unfortunately, several methodological problems may exist in the aforementioned study that may influence the generalizability of results and conclusions and impede its broader clinical use. In this study, we discuss in detail methodological problems and rationale for caution by analyzing reported studies, aiming to help the promotion of future well-powered trials.

Helicobacter pylori infection is a major health concern worldwide, especially in many resourcepoor countries, particularly in Africa and Latin America/Caribbean, such that more than half of the global population was infected with the pathogen H. pylori in 2015 (1). Gastric cancer (for which stomach adenocarcinoma accounts for around $90 \%$ of cases) is a life-threatening disease, which may be prevented by pharmacological approaches such as aspirin and non-pharmacological approaches such as gastric endoscopy (1). Basic and clinical studies have demonstrated strong associations between oncogenesis and the presence of $H$. pylori bacteria in the stomach; this includes the progression of pre-cancerous lesions (2). Remarkably, the proportion of non-cardia gastric cancer attributable to $H$. pylori increased from 74.7 to $89.0 \%$ from 2008 to 2014 (3). Furthermore, other epidemiologic factors, such as metabolic syndrome, are increasingly implicated in the etiology of gastric cancer (4). Importantly, H. pylori infection has also been linked to non-gastric diseases, including Parkinson's disease (5). The eradication of H. pylori using antibiotic therapy may prevent gastric cancer; such treatment has been implemented with varying levels of success globally (6).

\section{ERADICATION OF HELICOBACTER PYLORI INFECTION AND RISK OF METACHRONOUS GASTRIC CANCER}

Received: 25 November 2018

Accepted: 31 January 2019

Published: 20 February 2019

Citation:

Mentis A-FA and Dardiotis E (2019) Helicobacter pylori Eradication for Metachronous Gastric Cancer: An Unsuitable Methodology Impeding

Broader Clinical Usage.

Front. Oncol. 9:90

doi: 10.3389/fonc.2019.00090

The timing of interventions is often considered a key factor in determining whether cancer therapy is successful or not and whether $H$. pylori eradication is beneficial. A recent review of clinical studies revealed that $H$. pylori eradication is associated with a significantly lower risk of gastric cancer, particularly in patients with atrophic and non-atrophic gastritis, rather than in those with intestinal metaplasia; however, maximal benefit is obtained when eradication is performed during the early stages of infection (7). While this might be challenging because the infection is not typically targeted in childhood, a recent review of clinical studies confirmed that there is a general belief among healthcare practitioners that $H$. pylori eradication can prevent gastric cancer when it is administered in pre-cancerous or early cancerous stages (i.e., before a "point of no return") (8). 
In a remarkable and highly visible clinical study, Choi et al. (9) reported significant reductions in the incidence of metachronous gastric cancer after $H$. pylori eradication therapy in patients with previously resected early gastric cancer, indicating that $H$. pylori infections can benefit from treatment at any stage, thus refuting the conventional concept of the "point of no return" (1). This exciting finding seems important in convincing physicians, patients, and stakeholders, in favor of preventive $H$. pylori eradication, who might be otherwise skeptical of such measures; moreover, it generally aligns with the findings of similar recently published studies in the literature (10).

\section{METHODOLOGICAL REMARKS IN THE RECENT CLINICAL TRIAL}

Previous critiques of this landmark study were focused on its scientific aspects (11). Unfortunately, we have identified several methodological problems in the study, which may impact the generalizability of the results and conclusion, regardless of whether the study is robust and/or can be replicated. Hence, there is a need for further evidence (or more rigorous clinical trials) regarding the promising role of $H$. pylori eradication in the prevention of metachronous gastric cancer.

More precisely, the study by Choi et al. (9) was a clinical trial in which $\sim 10 \%$ of the patients developed gastric cancer, and a statistically significant difference was noted between the treated and untreated groups $(P=0.03)$. The authors reported a highly significant $(P<0.001)$ change in the atrophy grade within the corpus lesser curvature, thereby fulfilling their primary objective.

A consistent limitation of clinical studies is the inability to replicate results (frequently known as the "reproducibility crisis"); this often occurs due to low statistical power and a tendency to overinterpret statistically significant results. The researchers (9) did not report whether multiplicity corrections were used, although such statistical analyses are increasingly used in leading scientific journals (12). Combined with the reports of individual patient data, despite opposing opinions (13), we suspect that this could have helped readers to evaluate whether there is a causal association between $H$. pylori eradication and metachronous cancer reduction more accurately. A recent study demonstrated that clinical study participants are typically amenable to sharing of their individual patient data (14); the provision of such additional data would help promote detailed meta-analyses and evaluate the robustness of important results.

The corpus lesser curvature, which showed significantly less atrophy in patients who underwent $H$. pylori eradication therapy, is one of many regions where stomach adenocarcinomas exist. In the Japanese Gastric Cancer Association classification system, the corpus lesser curvature comprises three of the 12 possible lymph node stations; together with the corpus upper curvature, it is considered a part of the N1 region (15). Cancer reduction solely in the corpus lesser curvature will not necessarily result in fundamental changes with respect to TNM staging. According to $\mathrm{Wu}$ et al. (16), $\sim 46 \%$ of stomach carcinomas diagnosed in the USA are located in stomach non-cardia regions; these encompass corpus lesser curvature, as well as the fundus, body, antrum, and corpus greater curvature. Non-cardia carcinoma is epidemiologically distinct from other gastric corpus cancers across different populations (17). Therefore, it is particularly notable that the authors (9) limited their analysis solely to the atrophic changes of the lesser curvature, and strong caution is advised before generalizing anti-cancer effects discerned in one form of gastric cancer from a specific population to other forms of gastric cancer and across populations. Furthermore, the authors concluded that there was a reduction in the incidence of metachronous gastric cancer and greater improvement in the grade of gastric glandular atrophy among patients who underwent $H$. pylori treatment than among patients who received placebo treatment, and this conclusion is consistent with their stated aims. However, to achieve more precise conclusions, Choi et al. (9) should have specified anatomical limitations in their conclusion, i.e., instead of the broader term "corpus," they could have used the term "lesser curvature," which has a stricter definition.

A particularly surprising aspect of the study by Choi et al. (9) was that only a single study pathologist performed diagnosis and biopsy evaluations, which is in direct contrast with recent trends in the cancer arena (18). To reduce potential bias in the analysis of results, especially in cases where a global conclusion is made based on clinicopathological examinations, a robust inter-rater reliability between different independent ("blinded") pathologists should have been reported, preferably combined with parallel reporting of their level and area of expertise; moreover, Cohen's kappa coefficient might have been used as a statistic to measure inter-rater agreement (19). Further caution may be appropriate because this study concurrently considered the Vienna 4.2 ["non-invasive carcinoma (carcinoma in situ)"] and 4.3 ("suspicious for invasive carcinoma") diagnostic categories. The latter evaluates the suspicion of cancer identification, and due to potential misclassification risks, they are not considered in this classification system typically (20). It is though important to acknowledge that the authors limited their primary outcome variable to gastric adenocarcinomas alone, thus facilitating comparisons with other studies. Diagnostic cultural differences are also well-known. For example, a Japanese pathologist might classify a carcinoma based on the presence of notable cytological alterations (carcinoma in situ), whereas an American pathologist might interpret this as high-grade dysplasia because invasions are absent.

Additionally, the authors of this study (9) should have provided a more comprehensive literature background for the 1year clinical cutoff that they used to define metachronous cancer to provide a sense of comparability, regardless of whether all the results are recorded at 5 years; notable examples include studies by Nakajima et al. (21), Park et al. (22), Abe et al. (23), and Boda et al. (24). These contrast with the more commonly used cutoff of 6 months (Moertel definition) (25). More broadly, future clinical research would have been benefited if standardized criteria were used [akin to those in the medical terminology, as discussed by Mentis and Papavassiliou (26)]; this is particularly applicable for the design of large-scale clinical trials. Indeed, it is clearly not appropriate to compare studies 
with different criteria; this poses a problem when aggregating data from different studies, for example in meta-analyses. Therefore, it impacts the ability to translate research findings into clinical practice.

\section{ADDITIONAL PATIENT AND PATHOGEN FACTORS THAT SHOULD HAVE BEEN CONSIDERED}

Gastric cancer prevalence is lower in the Western hemisphere than in the Eastern hemisphere (9). An important factor associated with risk might be the $H$. pylori genotype. The CagA+, VacA s1, and VacA m1 H. pylori strains are associated with an increased risk of gastric cancer (27). In Asia, specific CagA polymorphisms exist; these trigger different biological mechanisms than those associated with polymorphisms found in other parts of the world (28). However, Western strains often intermix with East Asian strains; this mixing has dramatic impacts on individual disease outcome (29). Genetic screening of $\mathrm{H}$. pylori would have been particularly useful in the study by Choi et al. (9) to help further identify individual patients who benefited from $H$. pylori eradication therapy, thus bridging precision medicine and public health (30). Interestingly, the association between CagA antibodies and gastric cancer development has been established for more than two decades (31). In parallel, any effects related to patient profiles, notably proinflammatory genetic makeup [reviewed in El-Omar (32)], are largely absent in the causal analysis of the clinical trial. Collectively, these data would have supported the evaluation of the relative contributions of patient and pathogen factors to the findings reported by Choi et al. (9).

\section{REFERENCES}

1. Venerito M, Vasapolli R, Rokkas T, Malfertheiner P. Gastric cancer: epidemiology, prevention, and therapy. Helicobacter (2018) 23:e12518. doi: 10.1111/hel.12518

2. Mera RM, Bravo LE, Camargo MC, Bravo JC, Delgado AG, RomeroGallo J, et al. Dynamics of Helicobacter pylori infection as a determinant of progression of gastric precancerous lesions: 16-year follow-up of an eradication trial. Gut (2018) 67:1239-46. doi: 10.1136/gutjnl-2016-311685

3. Plummer M, Franceschi S, Vignat J, Forman D, de Martel C. Global burden of gastric cancer attributable to Helicobacter pylori. Int J Cancer (2015) 136:487-90. doi: 10.1002/ijc.28999

4. Li F, Du H, Li S, Liu J. The association between metabolic syndrome and gastric cancer in Chinese. Front Oncol. (2018) 8:326. doi: $10.3389 /$ fonc. 2018.00326

5. Dardiotis E, Tsouris Z, Mentis AFA, Siokas V, Michalopoulou A, Sokratous M, et al. H. pylori and Parkinson's disease: meta-analyses including clinical severity. Clin Neurol Neurosurg. (2018) 175:16-24. doi: 10.1016/j.clineuro.2018.09.039

6. Fuccio L, Zagari RM, Eusebi LH, Laterza L, Cennamo V, Ceroni L, et al. Meta-analysis: can Helicobacter pylori eradication treatment reduce the risk for gastric cancer? Ann Intern Med. (2009) 151:121-8. doi: 10.7326/0003-4819-151-2-200907210-00009

7. Rokkas T, Rokka A, Portincasa P. A systematic review and meta-analysis of the role of Helicobacter pylori eradication in preventing gastric cancer. Ann Gastroenterol. (2017) 30:414-23. doi: 10.20524/aog.2017.0144

\section{CONCLUSION}

The hypothesis tested by Choi et al. (9) is critical for improved treatment; moreover, the importance of increasing knowledge regarding $H$. pylori eradication as preventive therapy for metachronous cancer can be cost-effective. Data have been generated for meta-analyses; however, the results cannot be generalized in their current state. Well-powered trials across different populations using the latest screening and biomarker tools available to profile individual cancer cases are needed to determine the proportion of the global population for whom $H$. pylori eradication therapy may be beneficial and cost-effective. From a clinical perspective, clinicians must also consider the risk of second primary malignancies in other body parts of patients with gastric cancer (33).

\section{AUTHOR CONTRIBUTIONS}

A-FM and ED conceived this opinion article. A-FM provided the initial content and draft for the manuscript, and ED enhanced the manuscript content with further literature and critical points. A-FM and ED revised the draft and approved the version to be published.

\section{ACKNOWLEDGMENTS}

The contribution of Dr. Andreas F. Mentis in critically reading the manuscript as well as of Dr. Dimitris Xanthos for his editing support in earlier drafts of the manuscript is highly acknowledged. This study was supported by the Alexander Onassis Foundation, which played no role in the concept, design of this study, and drafting or revising of this manuscript.

8. Cheung KS, Leung WK. Risk of gastric cancer development after eradication of Helicobacter pylori. World J Gastrointest Oncol. (2018) 10:115-23. doi: 10.4251/wjgo.v10.i5.115

9. Choi IJ, Kook MC, Kim YI, Cho SJ, Lee JY, Kim CG, et al. Helicobacter pylori therapy for the prevention of metachronous gastric cancer. $N$ Engl J Med. (2018) 378:1085-95. doi: 10.1056/NEJMoa1708423

10. Choi JM, Kim SG, Choi J, Park JY, Oh S, Yang HJ, et al. Effects of Helicobacter pylori eradication for metachronous gastric cancer prevention: a randomized controlled trial. Gastrointest Endosc. (2018) 88:475-485.e2. doi: 10.1016/j.gie.2018.05.009

11. Pellicano R, Fagoonee S. Helicobacter pylori and prevention of gastric cancer. N Engl J Med. (2018) 378:2244-5. doi: 10.1056/ NEJMc1805129

12. Cristea IA, Ioannidis JPA. $P$-values in display items are ubiquitous and almost invariably significant: a survey of top science journals. PLoS ONE (2018) 13:e0197440. doi: 10.1371/journal.pone.0197440

13. Hoffmann T, Glasziou P, Beller E, Goldacre B, Chalmers I. Focus on sharing individual patient data distracts from other ways of improving trial transparency. BMJ (2017) 357:j2782. doi: 10.1136/bmj.j2782

14. Mello MM, Lieou V, Goodman SN. Clinical trial participants' views of the risks and benefits of data sharing. N Engl J Med. (2018) 378:2202-11. doi: 10.1056/NEJMsa1713258

15. Sitarz R, Skierucha M, Mielko J, Offerhaus GJA, Maciejewski R, Polkowski WP. Gastric cancer: epidemiology, prevention, classification, and treatment. Cancer Manag Res. (2018) 10:239-48. doi: 10.2147/CMAR.S149619 
16. Wu H, Rusiecki JA, Zhu K, Potter J, Devesa SS. Stomach carcinoma incidence patterns in the United States by histologic type and anatomic site. Cancer Epidemiol Biomarkers Prev. (2009) 18:1945-52. doi: 10.1158/1055-9965.EPI-09-0250

17. Camargo MC, Anderson WF, King JB, Correa P, Thomas CC, Rosenberg PS, et al. Divergent trends for gastric cancer incidence by anatomical subsite in US adults. Gut (2011) 60:1644-9. doi: 10.1136/gut.2010.236737

18. Elmore JG, Tosteson AN, Pepe MS, Longton GM, Nelson HD, Geller B, et al. Evaluation of 12 strategies for obtaining second opinions to improve interpretation of breast histopathology: simulation study. $B M J$ (2016) 353:i3069. doi: 10.1136/bmj.i3069

19. McHugh ML. Interrater reliability: the kappa statistic. Biochem Med. (2012) 22:276-82. doi: 10.11613/BM.2012.031

20. Tominaga K, Fujinuma S, Endo T, Saida Y, Takahashi K, Maetani I. Efficacy of the revised Vienna classification for diagnosing colorectal epithelial neoplasias. World J Gastroenterol. (2009) 15:2351-6. doi: 10.3748/wjg.15.2351

21. Nakajima T, Oda I, Gotoda T, Hamanaka H, Eguchi T, Yokoi C, et al. Metachronous gastric cancers after endoscopic resection: how effective is annual endoscopic surveillance? Gastric Cancer (2006) 9:93-8. doi: 10.1007/s10120-006-0372-9

22. Park JY, Kim SG, Kim J, Han SJ, Oh S, Choi JM, et al. Risk factors for early metachronous tumor development after endoscopic resection for early gastric cancer. PLoS ONE (2017) 12:e0185501. doi: 10.1371/ journal.pone.0185501

23. Abe S, Oda I, Minagawa T, Sekiguchi M, Nonaka S, Suzuki H, et al. Metachronous gastric cancer following curative endoscopic resection of early gastric cancer. Clin Endosc. (2018) 51:253-9. doi: 10.5946/ ce.2017.104

24. Boda $\mathrm{T}$, Ito $\mathrm{M}$, Oka S, Kitamura $\mathrm{Y}$, Numata $\mathrm{N}$, Sanomura $\mathrm{Y}$, et al. Characteristics of metachronous gastric tumors after endoscopic submucosal dissection for gastric intraepithelial neoplasms. Gastroenterol Res Pract. (2014) 2014:863595. doi: 10.1155/2014/863595

25. Kim JH, Rha SY, Kim C, Kim GM, Yoon SH, Kim KH, et al. Clinicopathologic features of metachronous or synchronous gastric cancer patients with three or more primary sites. Cancer Res Treat. (2010) 42:217-24. doi: $10.4143 /$ crt.2010.42.4.217
26. Mentis AFA, Papavassiliou AG. Correcting "insertion-deletion mutations" in medical terminology. J Cell Mol. (2018) 22:6408-9. doi: 10.1111/jcmm.13875

27. Matos JI, de Sousa HA, Marcos-Pinto R, Dinis-Ribeiro M. Helicobacter pylori CagA and VacA genotypes and gastric phenotype: a meta-analysis. Eur J Gastroenterol Hepatol. (2013) 25:1431-41. doi: 10.1097/MEG.0b013e328364b53e

28. Mueller D, Tegtmeyer N, Brandt S, Yamaoka Y, De Poire E, Sgouras D, et al. cSrc and c-Abl kinases control hierarchic phosphorylation and function of the CagA effector protein in Western and East Asian Helicobacter pylori strains. J Clin Invest. (2012) 122:1553-66. doi: 10.1172/JCI61143

29. Breurec S, Guillard B, Hem S, Papadakos KS, Brisse S, Huerre M, et al. Expansion of European vacA and cagA alleles to East-Asian Helicobacter pylori strains in Cambodia. Infect Genet Evol. (2011) 11:1899-1905. doi: 10.1016/j.meegid.2011.08.007

30. Mentis AFA, Pantelidi K, Dardiotis E, Hadjigeorgiou GM, Petinaki E. Precision medicine and global health: the good, the bad, and the ugly. Front Med. (2018) 5:67. doi: 10.3389/fmed.2018.00067

31. Huang JQ, Zheng GF, Sumanac K, Irvine EJ, Hunt RH. Meta-analysis of the relationship between cagA seropositivity and gastric cancer. Gastroenterology (2003) 125:1636-44. doi: 10.1053/j.gastro.2003.08.033

32. El-Omar EM. Role of host genes in sporadic gastric cancer. Best Pract Res Clin Gastroenterol. (2006) 20:675-86. doi: 10.1016/j.bpg.2006.04.006

33. Shah BK, Khanal A, Hewett Y. Second primary malignancies in adults with gastric cancer - a US population-based study. Front Oncol. (2016) 6:82. doi: $10.3389 /$ fonc. 2016.00082

Conflict of Interest Statement: The authors declare that the research was conducted in the absence of any commercial or financial relationships that could be construed as a potential conflict of interest.

Copyright (c) 2019 Mentis and Dardiotis. This is an open-access article distributed under the terms of the Creative Commons Attribution License (CC BY). The use, distribution or reproduction in other forums is permitted, provided the original author(s) and the copyright owner(s) are credited and that the original publication in this journal is cited, in accordance with accepted academic practice. No use, distribution or reproduction is permitted which does not comply with these terms. 